\title{
A IMPLANTAÇÃO DA GEOGRAFIA UNIVERSITÁRIA NO RIO DE JANEIRO
}

\author{
MÔNICA SAMPAIO MACHADO* \\ Universidade do Estado Rio de Janeiro
}

A estrutura universitária brasileira é uma construção relativamente recente, principalmente se compararmos ao desenvolvimento universitário europeu. No Brasil, embora as primeiras faculdades tenham surgido a partir da transferência da Corte Portuguesa em 1808 e a idéia de criação de uma universidade tenha começado a tomar corpo a partir de 1815, com a elevação do Brasil à condição de Reino, o surgimento das primeiras universidades ocorrerá somente após a proclamação da República (1889), mais precisamente, entre 1909 a 1928. Essas universidades haviam sido fundadas a partir de escolas isoladas como uma mera agregação, e, portanto, não lograram êxito ${ }^{1}$.

\footnotetext{
* Professora do Departamento de Geografia da Universidade do Estado do Rio de Janeiro e Doutoranda na Universidade de São Paulo.

${ }^{1}$ No Brasil a instituição universidade é uma criação do início do século vinte, entretanto é possível afirmar que desde o Brasil Colônia existiam cursos superiores (no sentido de um saber dominante superior, isto é, do domínio de práticas letradas mais complexas e da filosofia). Tratavam-se de cursos de artes e teologia primeiramente nos colégios jesuítas da Bahia, Rio de Janeiro, São Paulo, Olinda, Recife, Maranhão e Pará e, posteriormente, nos Conventos dos frades franciscanos no Rio de Janeiro e em Olinda. A partir de 1808, com a transferência da sede do poder metropolitano para o Brasil, especificamente para o Rio de Janeiro, e a emergência do Estado Nacional, registra-se o início de um novo ensino superior. São criados, no Brasil Império, cursos de anatomia e cirurgia nos hospitais militares (1808) e de engenharia na Academia Militar (1810). Outros cursos como de agronomia, química, desenho técnico, economia política, arquitetura e de direito, também surgem no início do século dezenove. Todos eram destinados a formar burocratas e especialistas para o Estado. Assim, pautada na estrutura do ensino superior montada no Brasil Império, surgem as primeiras faculdades: em 1832 as Faculdades de Medicina da Bahia e do Rio de Janeiro, em 1874 a Escola Politécnica no Rio de Janeiro, destinada ao ensino de engenharia civil e as suas especialidades (aqui formavam-se os denominados à época de geógrafos - engenheiros geógrafos) e, em 1854 as faculdades de direito em Recife e São Paulo. Embora existam registros
} 
Efetivamente, as primeiras universidades brasileiras que conseguiram fixar as bases da atual estrutura universitária nacional surgem no âmbito da política-institucional erigida no primeiro governo Getúlio Vargas (1930-1945). Em 1934 é implantada em São Paulo a Universidade de São Paulo e, em 1935, é implantada no Rio de Janeiro, então capital da República, a Universidade do Distrito Federal ${ }^{2}$, hoje Universidade Federal do Rio de Janeiro.

A institucionalização da geografia universitária brasileira ocorre a partir destes dois novos pólos de produção científica nacional. O pólo universitário "paulista" e o pólo universitário "carioca". Tanto a Universidade de São Paulo quanto a Universidade do Distrito Federal possibilitaram a implantação da geografia moderna no Brasil e impulsionaram a formação de duas escolas representativas da geografia nacional: $a$ escola paulista e a escola carioca de geografia. Procurando dar uma contribuição à história e memória da geografia brasileira, este artigo se limitará a apresentar algumas considerações sobre a implantação da geografia universitária no Rio de Janeiro, isto é, a Geografia desenvolvida a partir da nova estrutura de ensino superior montada nos anos de 1930, na era Vargas. Será apresentado o grupo inicial da comunidade científica dos geógrafos acadêmicos do Rio de Janeiro e os vínculos, à época estabelecidos na universidade, entre a Geografia e a História. Serão também destacados alguns fatores externos referentes à política-institucional erigida no Governo Getúlio Vargas que assinalam a fixação e expansão da estrutura universitária nacional.

\footnotetext{
de sucessivas tentativas de reunir as faculdades em uma universidade, o ensino superior brasileiro,que fora recriado a partir de 1808, constituiu-se com base em estabelecimentos isolados, dificultando em muito a criação da instituição universidade. Com a proclamação da República (1889), criando uma ordem jurídica que libera antigos anseios federativos, emergem, sem lograrem êxito, iniciativas isoladas de criação de universidades em diversos estados: no Amazonas em 1909, em São Paulo em 1911, no Paraná em 1912, no Rio de Janeiro em 1920, em Minas Gerais em 1927 e no Rio Grande do Sul em 1928. Nos três primeiros estados (Amazonas, São Paulo e Paraná) as universidades, consideradas por Cunha (1980:177) como passageiras, se dissolveram e não conseguiram se reproduzir, as universidades que surgiram posteriormente nada herdaram destas iniciativas. Já as universidades dos outros estados mencionados (Rio de Janeiro, Minas Gerais, Rio Grande do Sul), mesmo tendo sido organizadas a partir da simples técnica de aglomeração, conseguiram ser sucedidas posteriormente doando parte de suas instalações às efetivas universidades, criadas a partir de 1930 no início da era Vargas. (CUNHA, 1980:11-204).

${ }^{2}$ A Universidade do Distrito Federal começa a funcionar em condições precárias de instalação, utilizando-se do espaço físico, tanto para realização de seus cursos quanto para utilização dos laboratórios, da Universidade do Rio de Janeiro. Esta se resumia a uma simples aglutinação de escolas não correspondendo ao modelo de universidade que se esperava (vide notas 1 e 21 ).
} 


\section{A modernização institucional no primeiro Governo Vargas (1930-1945) e a busca da nova nacionalidade}

Os anos de 1930 marcaram de forma significativa a vida política-econômica e cultural brasileira. Sob comando de Getúlio Vargas ${ }^{3}$, grandes transformações foram operadas na sociedade e no Estado brasileiros determinando os rumos posteriores do país. A partir dos anos 30, deixando a condição agrário-exportadora, o Brasil transforma-se em um país urbano-industrial e produz um novo modelo institucional que permitiu não só a construção de sua unidade nacional, mas, sobretudo, da nova sociedade brasileira. São criados, entre 1930 a 1945, pelo governo federal, comissões, conselhos, departamentos, institutos, companhias, fundações, planos de desenvolvimento econômico e cultural, promulgadas leis e decretos, enfim, são geradas e postas em prática uma série de instituições e medidas ${ }^{4}$.

O modelo institucional, produzido por esse novo Estado brasileiro, um Estado capitalista-industrial que proclamava a necessidade de um governo forte, capaz de combater os particularismos de ordem local ${ }^{5}$, defendidos pela aristocracia agrária e intervir direta e intensamente na economia, estava claramente associado aos anseios centralizadores e nacionalistas que dominavam o cenário político, principalmente, entre os anos que caracterizam o Estado Novo (1937 a 1945). A crescente centralização do poder e a dimensão nacionalista se manifestam na criação de inúmeros órgãos administrativos de caráter regulador atingindo diversos setores da sociedade (IANNI, 1979).

O surgimento de tais órgãos vinculava-se, assim, às novas características assumidas pelo Estado: um Estado promotor, organizador e mecenas do mundo econômico e cultural. Ampliando suas atividades, o Estado organiza importantes instituições, das quais cabem mencionar algumas. Dos principais órgãos implantados pelo governo federal só na década de 1930, destacam-se: o Ministério de Educação e Saúde (hoje separado em Ministério da Educação e Ministério da Saúde), o Ministério do Trabalho, Indústria e Comércio (hoje separado em Ministério da Previdência e

${ }^{3}$ Getúlio Vargas governou o Brasil por duas vezes: de 1930-1945 e de 1951-1954, ano de sua morte. Presidente do Brasil de maior influência na história nacional, Vargas foi chefe do governo provisório (1930-1934), presidente da República eleito pela Constituinte (1934-1937), ditador do Estado Novo (1937-1945), presidente da República eleito com apoio das massas (1951-1954).

4 Sobre o governo Getúlio Vargas há uma extensa literatura que apresenta diferentes contribuições e análises. Destacaremos aqui algumas referências bibliográficas que fizeram parte de consulta deste artigo: Ianni, 1979; Fausto, 1970; Fonseca, 1989; Schwartzmann, 1982; D’Araújo, 1999.

${ }^{5}$ Em 1930, com Getúlio Vargas, institui-se o poder centralista e o governo federal foi deixando de ser o coordenador de forças regionais que exerciam um poder discricionário, através de grupos empresariais de pressão, nas cidades, e dos “coronéis" para exercer, ele próprio, o arbítrio. Conforme Darcy Ribeiro (1985), é o começo do desmonte da estrutura de poder da Primeira Republica (1889-1930), assentada nas chefaturas estaduais de coronéis fazendeiros que lideravam grupos de famílias. 
Assistência Social e Ministério do Trabalho) em 1930; a Universidade do Distrito Federal (incorporada, em 1939, pela Universidade do Brasil e, em 1965, transformada na atual Universidade Federal do Rio de Janeiro) em 1935; o Instituto Nacional de Pedagogia (hoje Instituto Nacional de Estudos e Pesquisas Educacionais, incorporado ao atual Ministério da Educação); o Serviço do Patrimônio Histórico e Artístico Nacional (hoje Secretaria do Patrimônio Histórico e Artístico Nacional, incorporada ao Ministério da Cultura) ${ }^{6}$, o Conselho Nacional de Geografia, em 1937; o Instituto Brasileiro de Geografia e Estatística (que incorpora o Conselho Nacional de Geografia) em $1938^{7}$.

Embora a modernização institucional tenha sido gerada entre 1930-1945 e as transformações no sentido de construção de uma política pública datarem deste período, algumas das principais mudanças vinham sendo lentamente geradas no bojo da Primeira República (1889-1930). Eram embriões de mudanças de origens e motivações diversas que convergiam numa aguda preocupação com relação à debilidade do Estado. Essas debilidades vinham sendo debatidas desde a I Guerra Mundial por intelectuais, políticos, empresários e militares. O projeto político e cultural sobre o qual o Estado Novo se assentou foi sendo, nesse sentido, elaborado entre 1920 a 1940 (OLIVEIRA, 1999). Frente à importância que os intelectuais desenvolveram neste projeto, especificamente, no caso da implantação da universidade, nos ocuparemos agora em traçar as principais matizes que sustentaram as atuações mais representativas da intelectualidade brasileira no período.

Para que fosse possível a criação de instituições verdadeiramente nacionais, governo e intelectuais, entre 1920 a 1930, pareciam estar de acordo com relação à importância e necessidade de aprofundar o conhecimento da cultura nacional. Como bem ressalta Octavio Ianni (1979), o nacionalismo estava presente em todos os (e diversificados) movimentos artísticos surgidos nos anos 20 , passando a ser estimulado oficial-

\footnotetext{
${ }^{6}$ A criação do Ministério da Educação e Saúde Pública e do Ministério do Ministério do Trabalho, Indústria e Comércio são exemplos ilustrativos dos objetivos de Vargas com relação à condução da modernização das instituições brasileiras. Getúlio Vargas assume o poder como presidente provisório em 3 de novembro de 1930; em 14 de novembro de 1930, pelo Decreto n. 19.402, cria o Ministério da Educação e Saúde e, em 26 de novembro de 1930, pelo Decreto 19.433, cria o Ministério do Trabalho, Indústria e Comércio (Ministério da Justiça: Arquivo Nacional; Cadastro Nacional de Arquivos Federais - volume I: Rio de Janeiro e Brasília. Arquivo Nacional. Presidência da República, Brasília).

${ }^{7}$ Cumpre assinalar que todas essas instituições foram implantadas no Rio de Janeiro, à época, capital da República. É possível inferir, portanto, que o Rio de Janeiro concentrava o poder decisório ao nível nacional e o ideal de construção da tão almejada identidade nacional. Assim, parece pertinente afirmar que, diferentemente de São Paulo, que possuía uma proposta regional/paulista para o país, o Rio de Janeiro historicamente se constituiu como pólo irradiador das propostas para o país como um todo. Era o local de gestação e difusão do pensamento nacional, em oposição inclusive ao pensamento nacional/regionalista, exemplificado pelo projeto nacional paulista. O Rio de Janeiro, pelo seu caráter cosmopolita, materializou o projeto nacional do governo federal. Nesse sentido, as universidades implantadas nestes dois estados promoverão projetos políticos também diferenciados.
} 
mente após 1930. O ambiente intelectual dos anos de 1920, marcado principalmente pela comemoração do Centenário da Independência do Brasil e a realização da Semana de Arte Moderna, ambas em $1922^{8}$, além de ter sido extremamente rico em manifestações, sugeriu a necessidade de transformação na vida brasileira a partir da construção de uma nova e "verdadeira" nacionalidade. A construção dessa nova nacionalidade torna-se debate efervescente no movimento modernista, movimento que redireciona a arte e a cultura brasileiras.

Como movimento intelectual de renovação no domínio da arte, o modernismo produziu consequiências diretas e importantíssimas no amplo domínio da cultura. Procurando combater o que existia antes, o modernismo englobava diferentes perspectivas que, segundo Oliveira (1999), podem ser organizadas em três posições: o movimento Verde-amarelo, vertente conservadora do modernismo paulista, que teve como proposta abandonar as influências européias e fixar a originalidade brasileira recorrendo aos mitos fundadores, ao mito tupi - aqui destacavam-se Cassiano Ricardo, Menotti del Pecchia e Plínio Salgado, defendendo a autenticidade da vida do interior em oposição à vida no litoral (uma forma de desqualificação do Rio de Janeiro) ${ }^{9}$; o movimento antropofágico (o antropófago come a carne de seus inimigos para captar suas energias) que propõe a apropriação das influências européias pelo canibalismo cultural, aqui destaca-se a figura de Oswald de Andrade, este é criticado por Tristão de Ataíde (pseudônimo de Alceu de Amoroso Lima) afirmando que suas propostas não passavam da pura importação do dadaísmo francês a o expressionismo alemão; a terceira posição é sintetizada pela via erudita de Mário de Andrade, que se dedica aos estudos do folclore e da música - dessa vertente sairá o grupo que criará mais tarde o Serviço de Patrimônio Histórico Nacional.

O modernismo, como movimento intelectual, caracterizou-se, assim, pela polarização de idéias como: região versus nação e tradição versus futuro - temas que estavam em pauta no debate para acordar o Brasil a criar a nação. Essas idéias dos anos 1920

\footnotetext{
${ }^{8}$ O ano de 1922 foi uma data simbólica da revolução estético-literária antecipadora da Revolução de 1930. O intelectual e o literato captaram antes dos outros a necessidade inconsciente de renovação da sociedade brasileira e a integração do modernismo. O novo Estado brasileiro estaria no fato da denúncia do Brasil arcaico e atrasado, marcado por duas características: novo (procura modernizar o país e pela primeira vez se voltando oficialmente para as raízes da nacionalidade) e nacional (OLIVEIRA, 1999).

${ }^{9}$ De acordo com Mônica P. Velloso (1996:13) no jornal Correio Paulistano (fins da década de 1910 e inícios de 1920) podem ser encontrados artigos, charges e caricaturas produzidas por ideólogos do grupo Verde-amarelo, cuja argumentação incidia sobre um mesmo ponto: a desqualificação da cidade do Rio de Janeiro em relação a São Paulo. Era afirmada a incapacidade do Rio para exercer seu papel de República por motivos tanto de ordem climática e econômica quanto cultural. A incapacidade para o exercício da hegemonia nacional era ressaltada em função do Rio de Janeiro localizar-se no litoral, ao contrário de São Paulo, no interior. Defendiam a idéia de que no litoral haveria uma profunda dispersão de energias produtivas que impediam o espírito empreendedor e administrativo e promoviam a incapacidade para o comando e a liderança.
} 
foram integradas sob novas condições e unificadas em um novo momento histórico, os anos 1930, permeando a modernização institucional e a construção do projeto universitário brasileiro. A década de 1930 pode ser pensada, nesse sentido, como um eixo em torno do qual girava o debate sobre a questão nacional, o que incluía pensar os rumos da política e da cultura brasileiras. Nesse momento, tanto as instituições, quanto artistas e intelectuais, de diferentes maneiras, norteados pelas idéias em ebulição, oriundas do movimento modernista, passaram a vivenciar ativamente uma grande preocupação com as questões sociais do país. O que pode ser evidenciado pelo leque de propostas ideológicas em curso, entre 1930 a 1937, sintetizado, principalmente, pelas temáticas desenvolvidas nos livros publicados no início dessa década. Eram temáticas que se referiam à crise brasileira, tanto diagnosticando-a quanto propondo diversas soluções. Discutia-se uma certa falência moral, econômica e social e buscava-se as virtudes básicas da nacionalidade. Aqui destacavam-se os escritores: Gilberto Freyre, José Américo de Almeida, José Lins do Rego, Sérgio Buarque de Holanda e Caio Prado Júnior (OLIVEIRA, 1999).

A busca dessas virtudes ficaria a cargo dos homens esclarecidos, de uma elite de cultura e ciência, capaz aos poucos de construir um pensamento dominante e influenciar a grande população brasileira. A crença de que essas elites, desde que recebam treinamento especializado, possam transformar o Brasil, é marcante na década de 1930. É nesta mesma década que são instaladas a Escola Livre de Sociologia e Política de São Paulo, a Universidade de São Paulo e a Universidade do Distrito Federal. Estas instituições de ensino superior, guardando suas devidas especificidades com relação aos seus projetos políticos, foram marcadas por esse espírito e revelam a complexidade do panorama intelectual daquele momento ${ }^{10}$. Essas universidades se constituíram como pólos privilegiados, entretanto diversificados, de construção e difusão do pensamento nacional. Cada uma, à sua maneira, buscava a questão nacional a partir de perspectivas e anseios distintos. Seus cursos, dessa forma, refletiam tal diversificação. Com o intuito de situar a geografia universitária implantada no Rio de Janeiro nesse debate, apresentaremos a seguir alguns dados históricos referentes à concepção e formação da Universidade do Distrito Federal.

\footnotetext{
${ }^{10}$ Diferente da Universidade do Distrito Federal, a Universidade do Estado de São Paulo, embora tenha sido implantada também na era Vargas, não veiculava o ideal centralizador presente nas propostas do Governo "getulista". Tanto a Escola de Sociologia e Política de São Paulo (criada em 27 de maio de 1933) quanto a Universidade de São Paulo (criada em 25 de janeiro de 1934), de acordo com Cunha (1980: 235-241), parecem ter sido criadas como um contraponto (paulista) ao governo central. Ambas tinham como objetivo preparar uma elite dirigente pelo valor técnico e moral, pois uma vez vencida pelas armas somente a ciência poderia auxiliar a exercer novamente a hegemonia desfrutada por São Paulo durante longas décadas no seio da Federação. A Escola de Sociologia foi implantada por representantes da oligarquia paulista derrotada na Revolução Constitucionalista de 1932 contra o Governo Vargas. A Universidade de São Paulo também tinha claros propósitos de reconquistar a hegemonia das oligarquias paulistas, perdida em 1932.
} 


\section{A Universidade do Distrito Federal: alguns dados históricos}

A Universidade do Distrito Federal (UDF) foi criada em 4 de abril de 1935, pelo Decreto 5.513, uma universidade mantida pela Prefeitura do Rio de Janeiro, então Distrito Federal. Instituída por Anísio Teixeira, a UDF nasce do conflito, de um lado dos projetos dos liberais, do qual Carneiro Leão, Fernando de Azevedo e o próprio Anísio Teixeira eram os representantes na política da educação, e, de outro lado, dos projetos dos conservadores representados por líderes católicos ativos como Francisco Campos e Alceu de Amoroso Lima. O conflito gerado por essas correntes levou o Governo a instituir a UDF por decreto, com intervenção direta do Presidente da República via gestão de Anísio Teixeira, na época à frente da Diretoria de Instrução Pública do Distrito Federal, no Governo de Pedro Ernesto, então Prefeito da capital da República (FÁVERO, 1989a: 20-28).

Nesse sentido, no momento da instalação da UDF houve uma certa vitória do projeto político dos liberais, defendido na figura de Anísio Teixeira. Este projeto sustentava-se no modelo educacional norte-americano desenvolvido no final da década da 1920, na Universidade de Columbia, pelo filósofo John Dewey. Anísio Teixeira, dando continuidade às reformas já iniciadas, institui um sistema educacional integral preconizado pela então Associação Brasileira de Educação $(\mathrm{ABE})^{11}$. Tratava-se da implantação de um verdadeiro sistema educacional integrado e completo, estendendose do pré-escolar, passando pelo curso primário, prosseguindo com uma educação secundária e culminando com a cúpula do ensino superior representada pela UDF.

Em discurso de inauguração dos cursos da UDF, em 1935, Anísio Teixeira afirmava a necessidade de estabelecimento da relação entre universidade, cultura e aperfeiçoamento da sociedade na direção da superação das distorções presentes nas atividades intelectuais do país, principalmente o isolacionismo acadêmico. Para Anísio Teixeira, a universidade se constituiria como fonte de formação da identidade de um povo e do caráter nacional. Nada mais natural construir isto a partir da UDF, sediada no Rio de Janeiro, então capital do país, indiscutivelmente um dos grandes pólos nacionais de irradiação cultural ${ }^{12}$. Caberia à UDF contribuir no combate ao autodidatismo e ao isolamento intelectuais, constituindo-se em núcleo de formação do quadro

\footnotetext{
${ }^{11}$ A Associação Brasileira de Educação (ABE) foi fundada em 1924 e representou a primeira e mais ampla forma de institucionalizar a discussão dos problemas da escolarização, em âmbito nacional. Em torno dela se reuniram as figuras mais expressivas entre os educadores, políticos, intelectuais e jornalistas, e sua ação se desdobrou na programação de cursos, palestras, reuniões e inquéritos, semanas de educação e conferências nacionais de educação. Foram por meio destas iniciativas que as preocupações com os problemas educacionais se alastram e as discussões se sistematizam (CUNHA, 1980:196)

12 O Rio de Janeiro desde o início da colonização, buscava se definir, conforme Angel Rama (1985), como uma cidade das letras, o lugar mais adequado à vivência do setor letrado acadêmico.
} 
intelectual do país, até aquele momento formado ao sabor do mais abandonado e mais precário autodidatismo (FÁVERO, 1989a:26).

A UDF foi pensada e implantada na capital do país reluzindo essas propostas. O Rio de Janeiro, assim, sediava uma universidade que tinha como objetivo constituir-se como fonte de formação da identidade e do caráter nacional do povo brasileiro. Sua instalação é aclamada por segmentos da intelectualidade brasileira que consideravam ter surgido na capital a instituição universitária mais vigorosa. Recebeu apoio de Afrânio Peixoto, Carneiro Leão, Roberto Marinho de Azevedo, Gustavo Lessa, Mário de Brito, Raul de A. Ribeiro e Junqueira Ayres.

Do corpo docente desta Universidade, destacavam-se intelectuais que compartilhavam a posição de Anísio Teixeira como Gilberto Freyre, Josué de Castro, Carlos Delgado de Carvalho, Heitor Villa-Lobos, Cecília Meirelles, Lúcio Costa, Carlos Leão e Cândido Portinari, mas também a figura de Alceu de Amoroso Lima, destacado representante da corrente conservadora. Passando a ter cada vez mais força política, Alceu de Amoroso Lima ${ }^{13}$, apoiado pela vertente católica, torna-se um dos principais responsáveis pela demissão de Anísio Teixeira do cargo de Diretor de Instrução, ainda em 1935, quatro meses após a inauguração da UDF, e da incorporação desta Universidade, em 1939, pela Universidade do Brasil (FÁ VERO, 1989a:17-71).

\section{A Geografia na Universidade do Distrito Federal}

A UDF foi constituída pelas Escolas de Ciências, de Economia e Direito e de Filosofia e Letras, pelos Institutos de Artes e de Educação e por instituições complementares que buscavam a experimentação pedagógica e prática de ensino, pesquisa e difusão cultural (FÁVERO, 1989a:26).

A Geografia unida à História constituía um só curso, o de Geografia e História, que se encontrava lotado na Escola de Economia e Direito. Esta tinha por finalidade desenvolver estudos sobre a organização econômica e social e constituir-se como centro de documentação e pesquisa dos problemas da vida nacional incluindo tanto a formação do Estado como a produção, circulação e distribuição da riqueza (FÁVERO, 1989a:62). Agrupava a Seção de Ciências Sociais e a Seção de Ciências Geográficas e

13 Alceu de Amoroso Lima assume a Reitoria da UDF em 1936, lugar ocupado por Afrânio Peixoto. Recebe apoio também de Francisco Campos, que sucede Anísio Teixeira na pasta de Secretário de Instrução Pública também em 1936. 
Históricas. A Seção de Ciências Sociais era composta pelas cadeiras de Antropologia, Economia Social, Biologia, Sociologia Geral e Psicologia Geral, enquanto a Seção de Ciências Geográficas e Históricas, pelas cadeiras de História da Antigüidade, História da Idade Média e Moderna, Geografia Humana e Fisiogeografia.

A implantação do Curso de Geografia e da História na UDF contou inicialmente com os esforços de Pierre Deffontaines e Lucien Febvre, pioneiros entusiastas dos primeiros anos, que procuravam desvendar aos estudantes o que eram Geografia e História nas suas múltiplas relações, projetadas e percebidas na "Paisagem Geográfica"14. Colaboraram também com o estabelecimento da geografia universitária carioca Carlos Delgado de Carvalho e Fernando Antônio Raja Gabaglia. O primeiro lecionando Geografia Humana e o segundo Fisiogeografia.

Pierre Deffontaines (1894-1978), um dos membros das missões francesas no Brasil, foi primeiramente contratado pela Universidade de São Paulo e, posteriormente, entre os anos de 1936 a 1938, passa a lecionar geografia na UDF (MORAES: 1999). No Rio de Janeiro, exerceu grande influência nos estudantes de geografia e nos geógrafos, promovendo nestes o incentivo para a criação do Conselho Nacional de Geografia e para a publicação da Revista Brasileira de Geografia, iniciada em 1939. Pertencendo a uma geração que havia recebido formação e inspiração dos grandes mestres franceses como Jean Brunhes, discípulo de Vidal de la Blache, Deffontaines implanta no Brasil a chamada "escola francesa de geografia" (BERNARDES, 1982). Perspectiva que fica clara logo nos primeiros números da Revista Brasileira de Geografia. Seus artigos descreviam a dimensão continental do Brasil e davam o tom da nova geografia acadêmica que estava sendo introduzida, a linha vidalina, onde a moldura do quadro natural comandava a organização das atividades humanas (DEFFONTAINES, 1939). De fato, estas preocupações estavam a serviço de um governo empenhado na centralização do poder, num país até então essencialmente agrário, extremamente segmentado em arquipélagos econômicos.

Carlos Delgado de Carvalho (1884-1980), intelectual de grande contribuição à geografia brasileira, foi também um dos principais responsáveis pela introdução e desenvolvimento de um setor geográfico moderno no Brasil. Esse papel pioneiro pode ser aferido através da qualidade de suas primeiras obras: Un Centre Économique au Brésil (Estado de Minas) (1908); Le Brésil Meridional: Etude Économique sur les Etats du Sud (1910) 15; Geographia do Brasil (1913); Météorologie du Brésil (1917); Physiografia do Brasil

\footnotetext{
14 Anuário do Instituto de Geociências da UFRJ (1995)

15 O clássico Le Brésil Meridional: Etude Économique sur les Etats du Sud (1910) apresentava um grau de elaboração ainda não visto nos estudos que eram desenvolvidos sobre o território brasileiro. De uma abordagem tradicional baseada na divisão e descrição de estados, o Brasil começava a ser estudado através de uma visão totalizadora que permitia agrupar em uma mesma região um conjunto de estados. "Le Brésil Méridional " levanta, reúne e interage os diferentes elementos naturais e humanos da porção subtropical do Brasil, propondo uma nova divisão territorial que, a partir das regiões naturais, se sobrepunha
} 
(1923), Introdução à Geografia Política (1925), Metodologia do Ensino Geográfico (1925). Embora tenham sido produzidas nas décadas de 1910 e 1920, só tiveram merecida repercussão posteriormente, nas décadas de 1930 e 1940, quando os estudos e as pesquisas geográficas tomam impulso, através da implantação dos cursos universitários de geografia e de sua incorporação na grade curricular das escolas secundárias, da fundação da Associação dos Geógrafos Brasileiros em São Paulo (criada em 1934 por Pierre Deffontaines) e da criação do sistema estatístico-geográfico-cartográfico do Instituto Brasileiro de Geografia e Estatística (IBGE) em $1938^{16}$.

A contribuição de Delgado de Carvalho, contudo, ultrapassa a Geografia. Além de geógrafo era historiador e sociólogo, formação que possibilitou sua atuação intelectual e mesmo política em diferentes campos de saber. No Brasil, dedicou-se primeiramente à Geografia, pelo total desconhecimento no país daquilo que poderia ser considerado um estudo geográfico científico (BERNARDES, 1982). Filho de brasileiros, Delgado de Carvalho, formado na Escola de Ciências Diplomáticas de Paris e na Escola de Economia e Política de Londres, chega ao Brasil em 1906 (CASTRO, 1993), com idéias liberais que coadunavam-se ao espírito de progresso e liberdade do homem presentes na época. Logo passa a se relacionar com a jovem intelectualidade progressista, colaborando com artigos e comentários junto à imprensa mais liberal do Rio de Janeiro (Notícia e o Jornal do Comércio) (FERRAZ, 1994:71).

Em 1924 funda, juntamente com Everardo Backeuser ${ }^{17}$, entre outros, a Associação Brasileira de Educação (ABE), da qual se faz presidente, estreitando laços de trabalho e amizade com outros liberais que pensavam a modernização educacional e aqui, conforme apontado anteriormente, destacava-se Anísio Teixeira ${ }^{18}$. Durante a década de 1920 aumenta sua dedicação à docência, principalmente no Colégio Pedro $\mathrm{II}^{19}$, minis-

aos limites político-administrativos dos Estados e aos interesses regionalistas de suas oligarquias agrárias. (MACHADO, 1999a)

${ }^{16}$ Sobre a criação do IBGE consultar Penha (1993)

${ }^{17}$ Everardo Backheuser (1879-1951), engenheiro, foi vice-presidente da Sociedade de Geografia do Rio de Janeiro e fundador da Academia Brasileira de Ciências. Participa na década de 1930 da reforma pedagógica do ensino brasileiro fundamentado nas idéias de John Dewey. Dedicou-se à geopolítica e às possibilidades de aplicação à política de reformas do Estado valorizando os estudos geográficos entre $1920 \mathrm{e}$ 1930. (MACHADO, 1995)

${ }^{18}$ A partir da ABE, Delgado de Carvalho estabelece aproximação entre intelectuais e alunos norte-americanos e brasileiros, fundando assim, juntamente com Carneiro Leão e Afrânio Peixoto, a Summer School, como forma de trazer estudantes americanos para o Brasil e levar educadores brasileiros para os EUA (FERRAZ, 1994:71)

${ }^{19}$ Cabe ressaltar a importância histórica do Colégio Pedro II. A forte relação entre d. Pedro II e o Colégio transformou esta instituição de ensino na única que escapava ao ensino excessivamente livresco, anticientífico e pouco abrangente, uma espécie de símbolo de civilidade, de um lado, e de pertencimento a uma elite, de outro. (SCHWARCZ, 1998). 
trando aulas de Geografia e Sociologia. Na década de 1930 assume cargos importantes no Conselho Nacional de Educação e no Instituto de Pesquisas Educacionais até 1935, quando é nomeado catedrático de Geografia Humana na UDF.

Fernando Antônio Raja Gabaglia (?-1954) apresentou também importantes contribuições para a renovação e difusão da geografia no Brasil. Juntamente com Delgado de Carvalho, Everardo Backheuser e outros professores e pesquisadores, objetivava fundar a nova escola de geografia e desenvolver uma classificação para o território e para a população brasileira. Em 1930, debruça-se na defesa da ciência geográfica através do projeto de restauração da geografia como ciência natural (MACHADO, 1995). Foi um dos estudiosos da temática estatal-territorial estabelecendo vinculações entre a pesquisa geográfica e o Estado. Para Raja Gabaglia, a disciplina Geografia auxiliaria a construção da sociedade, uma vez que instrumentalizaria as atividades do Estado na execução de estradas, nos mapeamentos, nos levantamentos de recursos, etc. Enfim, a disciplina Geografia forneceria ao Estado um domínio do território e, consequentemente, a possibilidade de realização da tão aclamada identidade nacional (RAJA GABALIA, 1947).

Teve grande atuação tanto no campo da geografia quanto no da política educacional brasileira. No campo geográfico, Fernando Antônio Raja Gabaglia foi professor do ensino secundário oficial (atuando no Colégio Pedro II), autor de livros didáticos e um dos fundadores do curso de geografia da Universidade do Estado do Rio de Janeiro, implantada posteriormente ${ }^{20}$. Na área da política educacional atuou como Secretário de Educação do Distrito Federal (em 1944) e como Diretor de Colégio Pedro II. Em constante atualização sobre as discussões geográficas dos centros internacionais de pesquisa à época, tanto Fernando Antônio Raja Gabaglia quanto seu irmão João Capistrano Raja Gabaglia (os irmãos Raja Gabaglia), ambos autodidatas, contribuíram também para a formação do Conselho Nacional de Geografia e do Instituto Brasileiro de Geografia e Estatística (IBGE).

A geografia universitária foi implantada, assim, no Rio de Janeiro a partir da institucionalização da UDF. Desenvolvida juntamente com a História, no curso de Geografia e História, contou não apenas com o mestre francês Pierre Deffontaines, como também com Carlos Delgado de Carvalho e Fernando Antônio Raja Gabaglia. Tratavam-se de geógrafos que pareciam não só defender a modernização do saber geográfico no Brasil, como também construir, a partir de seus estudos, eminentemente espaciais, uma perspectiva territorial para a nova nacionalidade brasileira. Esta entendida não a partir da ótica e de interesses regionais, mas sim do ideal de uma identidade nacional capaz de integrar em um grande projeto os diferentes segmentos sócioespaciais que constituíam o Brasil.

\footnotetext{
${ }^{20}$ Sobre a implantação da geografia na UERJ ver Machado, (1999b)
} 


\section{A Geografia na Universidade do Brasil}

A UDF foi extinta em 1939, dois anos após a institucionalização da Universidade do Brasil. A Universidade do Brasil, instituição federal criada pela Lei ${ }^{\circ} 452$ de julho de 1937, acaba congregando, além das faculdades isoladas e escolas já existentes, a Universidade do Rio de Janeiro ${ }^{21}$ e os cursos que haviam sido implantados na UDF. Estes constituíram a Faculdade Nacional de Filosofia da Universidade do Brasil, que teve sua organização definitiva com o Decreto $\mathrm{n}^{\circ} 1190$ de abril de 1939. Apesar da efêmera vida de quatro anos, a UDF foi responsável pela criação de um ambiente favorável à implantação da Faculdade Nacional de Filosofia da Universidade do Brasil, pois constituiu-se como viveiro de capacidade intelectual do Brasil, o que acabou impondo a necessidade da existência, na capital Federal, de uma faculdade à sua altura, na qual a cultura encontrasse a sua forma mais alta e desinteressada.

Foram transferidos da UDF para a Faculdade Nacional de Filosofia da Universidade do Brasil, não apenas os espaços e a infra-estrutura existentes, como também os recursos humanos (professores e alunos). Representando um importante pólo intelectual do Rio de Janeiro, à época, a Faculdade Nacional de Filosofia se organizou a partir de quatro seções ou departamentos: Filosofia (curso de Filosofia); Letras (com os cursos de: Letras Clássicas, Letras Neolatinas, Letras AngloGermânicas); Pedagogia (curso de Pedagogia); e Ciências (com os cursos de: Matemática, Química, Física, História Natural, Geografia e História, Ciências Sociais). Manteve onze cursos estruturados em três séries mais uma (correspondendo ao curso de didática) e formou bacharéis e licenciados nas diversas áreas. Até 1945, a Faculdade Nacional de Filosofia buscou sua implantação instalando laboratórios, museus especializados, linhas de pesquisas e práticas de trabalho de campo e de laboratório. Ampliou seu quadro docente, recorrendo à contratação de professores estrangeiros com o intuito de introduzir e desenvolver a pesquisa aliada à atividade de ensino, algo que o Brasil ainda não dispunha. Destacavam-se na área de ciências humanas e sociais os mestres franceses.

Os estímulos que as primeiras gerações de estudantes de Geografia receberam para continuar sua carreira profissional estavam atrelados não só ao processo de modernização institucional, o que incluía o sucesso dos cursos universitários de geografia e os órgãos de pesquisa implantados, mas também ao papel desenvolvido por esses mestres franceses.

${ }^{21}$ A Universidade do Rio de Janeiro foi fundada em 1920, pela reunião da Escola Politécnica, da Faculdade de Medicina e da Faculdade de Direito. Parece que esta Universidade, criada por decreto, resultou de uma necessidade diplomática de conferir o título de honoris causa ao Rei Alberto da Bélgica, que visitava o Brasil naquele momento. Tratava-se de uma justaposição de escolas existentes reunidas sob uma reitoria recém-criada: uma universidade atomizada, sem integração entre as unidades de ensino, uma universidade "de fachada" resumindo-se apenas a um conjunto complexo e contraditório. (CUNHA 1980:189-190) 
Em 1939 é contratado para lecionar a cadeira de Geografia Humana o francês André Gilbert que fica no Brasil apenas um ano. Em 1941, Francis Ruellan, o segundo grande mestre francês após Deffontaines, ao chegar no Rio de Janeiro para lecionar na universidade (MONTEIRO, 1980:11), é contratado para ministrar um curso especial. Também, nesse mesmo ano, entram na Faculdade de Filosofia para lecionarem Geografia os brasileiros Victor Ribeiro Leuzinger (engenheiro - professor catedrático interino de Geografia Física) e Josué de Castro (médico - professor catedrático interino de Geografia Humana) .

Carlos Delgado de Carvalho é transferido para a Universidade do Brasil como professor catedrático interino de Geografia do Brasil. Entretanto, em 1943, é exonerado, retornando em 1945 como professor catedrático efetivo para lecionar as cadeiras de História Moderna e História Contemporânea. Em 1945 é também contratado, como professor catedrático interino, Hilgard Sternberg (geógrafo/UB e PHD/Berkeley) para ministrar a disciplina Geografia do Brasil (FÁVERO, 1989B:44).

Francis Ruellan (1894-1975) trabalhou no Rio de Janeiro entre 1940 e 1956, formando a segunda geração de geógrafos. Desenvolveu o ensino e a pesquisa em Geografia, particularmente em Geomorfologia, em articulação com investigações que dirigia na condição de Assistente Técnico do Conselho Nacional de Geografia. Proporcionou a aproximação dos estudantes de Geografia da Faculdade de Filosofia, através de suas pesquisas com o Conselho Nacional, criando espaços para as carreiras de geógrafos. Organizou trabalhos de campo que permitiram acumular conhecimento empírico sobre o território brasileiro e sobre sua ocupação. Esse levantamento empírico (do Paraná a Roraima) foi fundamental para o desenvolvimento profissional do grupo de geógrafos do Rio de Janeiro e para a construção do pensamento sobre o Brasil em termos de grandes conjuntos geográficos, o que sem dúvida era essencial para um país muito extenso e pouco conhecido geograficamente.

Josué de Castro (1908-1973) foi professor catedrático de Antropologia da UDF entre 1935 e 1938 e professor catedrático de Geografia Humana da Faculdade de Filosofia da Universidade do Brasil entre 1940-1964. A contribuição de Josué de Castro é reconhecida mundialmente, não só pela sua capacidade intelectual, mas também por sua expressiva personalidade política. Realizou várias conferências sobre problemas relativos a alimentação e nutrição em diferentes países entre 1939 a 1947. Assumiu cargos importantes na ONU e foi Deputado Federal em 1954 a 1964. Autor de vários livros, dos quais dois tiveram grande repercussão mundial, Geografia da Fome e Geopolítica da Fome, traduzidos em diferentes idiomas. Sua contribuição transcende não só a Geografia mas o circuito universitário. Preocupou-se com as disparidades sócio-espaciais, chamando atenção para a temática da fome no Brasil e no mundo, transformando-a em fato político.

Embora o alcance de sua atuação tenha extrapolado o campo de saber da Geografia, Josué de Castro desempenhou também significativa colaboração à modernização e difusão da ciência geográfica brasileira. Em 1945, defendia para a Geografia um ensino universitário moderno, o que implicava ir além da pura descri- 
ção e enumeração dos fenômenos naturais e culturais presentes na superfície terrestre. Era necessário capacitar os estudantes à classificação científica dos fenômenos, objetivando a construção de explicações das diferenças espaciais existentes no território nacional. Para tanto, o ensino teórico e as atividades práticas eram fundamentais. A aspiração de Josué de Castro centrava-se na formação de dois grupos de geógrafos brasileiros: um identificado com métodos pedagógicos e outro mais familiarizado com os métodos de indagação científica. Estes, poderiam cooperar para a ampliação do conhecimento dos problemas brasileiros, uma vez que muitos dos alunos saídos da Faculdade de Filosofia já haviam sido aproveitados pelo Conselho Nacional de Geografia.

Hilgard Sternberg, bastante preocupado com o ensino e a pesquisa em Geografia, tendo como objetivo central o desenvolvimento de um conhecimento sobre a realidade espacial brasileira, cria em 1952, o Centro de Pesquisas de Geografia do Brasil (CPGB), como órgão anexo à disciplina que lecionava (Geografia do Brasil). Vinculado diretamente à reitoria, o CPGB teve apoio da Fundação Rockefeller e da própria Universidade. Nos primeiros dez anos o CPGB desenvolveu suas atividades primeiramente elaborando um Relatório interdisciplinar sobre a Conservação da Natureza no Brasil, por solicitação da Associação Internacional de Proteção à Natureza, sediada em Bruxelas. Em seguida, assume como Projeto a Biblioteca Cartográfica e a Bibliografia Geográfica do Brasil, cuja publicação passou a representar valioso elemento de intercâmbio com pesquisadores de outras instituições de pesquisa nacionais e estrangeiras ${ }^{22}$.

A partir de 1955, com a Lei 2594, a Geografia desenvolvida na Faculdade de Filosofia da Universidade do Brasil desvincula-se da História. São organizados dois cursos separados: o Curso de Geografia e o Curso de História. Com relação à Geografia, esta modificação promove necessariamente mudança e ampliação de seu corpo docente. A partir da saída da capital Federal do Rio de Janeiro para Brasília, em 1960, processam-se mudanças referentes à nomenclatura da Universidade do Brasil que, em 1965, passa a se chamar Universidade Federal do Rio de Janeiro (UFRJ) ${ }^{23}$. Com a Reforma Universitária de 1967/68, implantada no Governo Militar, o curso de Geografia é realocado em uma nova unidade de ensino, no Instituto de Geociências, distanciando-se das ciências sociais e aproximando-se das ciências da natureza.

\footnotetext{
${ }^{22}$ Anuário do Instituto de Geociências da UFRJ (1995).

${ }^{23}$ Com relação à data de mudança da nomenclatura da Universidade do Brasil para Universidade Federal do Rio de Janeiro encontramos informações diferentes. Segundo Lobo (1980:49), com a saída da capital Federal do Rio de Janeiro para Brasília em 1960, é promulgada em 1961 a Lei 4020, conhecida como Lei de Diretrizes e Bases, mudando o nome da UB. Entretanto, de acordo com Fávero (2000a: 99-105), a mudança de nome da Universidade do Brasil para Universidade Federal do Rio de Janeiro ocorre em 1965, através da Lei 4831, sancionada em 5 de novembro. Conforme Fávero (2000a:14), para se chegar a esta conclusão foi solicitada a colaboração do Centro de Documentação de Estudos Legislativos da Câmara de Deputados - Seção de Documentação Parlamentar, em Brasília, onde foi possível obter a
} 


\section{Considerações finais}

Objetivando dar uma contribuição à história institucional da geografia brasileira, procurou-se sistematizar algumas informações sobre a geografia universitária desenvolvida no Rio de Janeiro. Em primeiro lugar, buscou-se localizá-la a partir dos grandes marcos da modernização institucional desenvolvida no primeiro Governo Getúlio Vargas, o que, necessariamente, incluiu tanto a discussão dos desdobramentos do modernismo no Brasil quanto, por conseguinte, o debate intelectual sobre a busca da nova nacionalidade, questões tão efervescentes nos anos de 1930. Em seguida, com intuito de conhecer as aproximações da geografia universitária com outros campos de saber, e portanto conhecer seus interlocutores mais próximos, procurou-se mapear a Geografia na estrutura universitária da então capital da República. É possível que sua vinculação com a História, especificamente, e com as ciências sociais, em geral, possa nos auxiliar na montagem do caráter dos estudos geográficos desenvolvidos no Rio de Janeiro nas primeiras décadas de sua institucionalização universitária.

Embora seja prematuro apresentar, nesse momento, conclusões sobre o caráter desses estudos, em função da falta de trabalhos empíricos com relação às temáticas geográficas desenvolvidas no período na universidade, é possível pensar que, diferentemente de São Paulo, o Rio de Janeiro, por ter sediado historicamente um ideal de construção nacional respaldado no modernismo de vertente carioca, procurava uma interpretação generalista do país, o que incluía investigar as diferentes realidades naturais, culturais e territoriais brasileiras. Era de interesse dos intelectuais sediados no Rio de Janeiro uma interpretação do Brasil construída a partir das suas diversidades e pouco se preocupavam com temas propriamente da cidade e da especificidade do Rio de Janeiro. De fato, parece que as atividades intelectuais cariocas foram incorporadas pelas agências culturais do Estado em busca de uma teoria sobre o Brasil. Nesse ponto, a geografia carioca parece ter tido papel preponderante. O que pode talvez ser explicado não apenas pela importância do Rio de Janeiro como pólo de decisões nacionais, como também pela aproximação, à época, da Geografia com as ciências sociais e com os órgãos implantados para a modernização do país como o Conselho Nacional de Geografia e o Instituto Brasileiro de Geografia e Estatística, que sempre estiveram vinculados ao caráter pragmático de subsídio político ao Estado.

Os intelectuais que constituíram o grupo inicial da comunidade científica de geógrafos acadêmicos no Rio de Janeiro, incluindo tanto os que contribuíram para a formação da Universidade do Distrito Federal quanto para a Universidade do Brasil (Pierre Deffontaines, Carlos Delgado de Carvalho, Fernando Antônio Raja Gabaglia,

Mensagem Presidencial e a Exposição de Motivos do Ministro da Educação, de agosto de 1965, que se referiam à mudança da denominação. Em função do livro de Fávero (2000b) apresentar os documentos referentes aos dispositivos legais da UB e, especificamente, a Lei 4831, localizamos a mudança de nomenclatura também no ano de 1965. 
Francis Ruellan, Hilgard Sternberg e Josué de Castro), embora tenham atuado em direções diferenciadas, parecem ter compartilhado, no tocante à Geografia, um grande projeto: implantar e difundir a geografia moderna no Brasil, utilizando-a na busca do conhecimento da realidade territorial brasileira, à época extremamente carente de investigações, conhecimento fundamental para a montagem da tão aclamada identidade nacional.

\section{A IMPLANTAÇÃO DA GEOGRAFIA UNIVERSITÁRIA NO RIO DE JANEIRO}

Resumo: O presente trabalho procura dar uma contribuição à história e memória da geografia brasileira. Será objeto de estudo deste artigo a implantação da geografia universitária desenvolvida no Rio de Janeiro, a partir de 1930, com a formação da Universidade do Distrito Federal, hoje Universidade Federal do Rio de Janeiro. Nossa intenção é descrever o processo de institucionalização da geografia universitária carioca apresentando o grupo inicial da comunidade científica dos geógrafos acadêmicos e os vínculos, à época estabelecidos, entre a Geografia e a História. Será dada particular ênfase aos fatores externos, especialmente, àqueles referentes à política-institucional erigida no primeiro Governo Getúlio Vargas (19301945), política esta que marca a fixação e expansão da estrutura universitária nacional.

Palavras-chave: Geografia brasileira; Geografia universitária carioca; História institucional; Universidade.

\section{THE IMPLANTATION OF UNIVERSITARY GEOGRAPHY IN RIO DE JANEIRO}

Summary: This work is a contribution to the history and the memory of Brazilian Geography. The geography developed at Universidade Federal do Rio de Janeiro since 1930, when it was created and known as Universidade do Distrito Federal, is the main concern of this study. We intend to describe the process of institutionalisation of academic geography developed in Rio de Janeiro, indicating the early group of scientific community of academic geographers and the linkages developed at that time between Geography and History. A peculiar emphasis on external aspects will be given, specially those related to the university institutional policies implemented/led by Getúlio Vargas's government, which can be seen as the one of the first steps for the fixation and expansion of Brazilian university structure.

Keywords: Brazilian geography; Academic geography in Rio de Janeiro; Institutional history; University.

\section{BIBLIOGRAFIA}

ALMEIDA, José Ricardo Pires de (1989): História da Instrução Pública no Brasil (1500-1889). São Paulo: INEP-SP.

BERNARDES, Nilo (1982): A influência estrangeira no desenvolvimento da Geografia no Brasil. In: Revista Brasileira de Geografia. Rio de Janeiro: IBGE. ano 44, n.3, jul./set. p.519-527.

CARVAlHO, Maria Rezende de Carvalho (1994): Quatro Vezes Cidade. Rio de Janeiro: Sette Letras.

CASTRO, Maria Terezinha de (1993): Carlos Delgado de Carvalho, mimeo. 
CUNHA, Luiz Antônio (1980): A Universidade Temporã: o ensino superior da Colônia à Era de Vargas. Rio de Janeiro: Editora Civilização Brasileira.

DAFFONTAINES, Pierre (1939): Geografia humana do Brasil. In: Revista Brasileira de Geografia. Rio de Janeiro: IBGE. 1(1,2,3).

FÁVERO, Maria de Lurdes de A. (2000a): Universidade do Brasil: das origens à construção. Rio de Janeiro: Editora UFRJ/Inep. , v.1.

FÁVERO, Maria de Lurdes de A. (org.) (2000b): Universidade do Brasil: guia dos dispositivos legais. Rio de Janeiro: Editora UFRJ/Inep. v.2.

FÁVERO, Maria de Lurdes de A. (coord.) (1989a): Faculdade Nacional de Filosofia: projeto ou trama universitária? (1). Rio de Janeiro: Editora UFRJ.

- (1989b): Faculdade Nacional de Filosofia: o corpo docente: matizes de uma proposta autoritária (2). Rio de Janeiro: Editora UFRJ.

(1989c): Faculdade Nacional de Filosofia: caminhos e descaminhos (3). Rio de Janeiro: Editora UFRJ.

- (1989d): Faculdade Nacional de Filosofia: os cursos (4). Rio de Janeiro: Editora UFRJ.

FERRAZ, Claudio Benito Oliveira. (1994): O discurso geográfico: a obra de Delgado de Carvalho no contexto da geografia brasileira - 1913 a 1942. São Paulo: Dissertação de mestrado apresentada ao Departamento de Geografia da FFLCH/USP.

FERREIRA, Marieta de Moraes (1999): Diário pessoal, autobiografia e fontes orais: a trajetória de Pierre Deffontaines. In: Primeiro Simpósio de História do Pensamento Geográfico. UNESP/Rio Claro. p.131-138.

FAUSTO, Boris (1970): A Revolução de 30. São Paulo: Brasiliense.

FONSECA, Pedro Cezar Dutra (1989): Vargas: o capitalismo em construção (19061954). São Paulo: Brasiliense.

GEIGER, Pedro Pinchas (1988): A industrialização e urbanização no Brasil, conhecimento e atuação da Geografia. In: Revista Brasileira de Geografia. Rio de Janeiro: IBGE. 50. $\mathrm{n}^{\circ}$ especial. 1.2:59-84.

IANNI, Octavio (1979): Estado e planejamento econômico no Brasil (1930-1970). Rio de Janeiro: Civilização Brasileira.

LAMOUNIER, Bolívar. O modelo institucional dos anos 30 ao fim da Era Vargas. In: D'ARAUJO, Maria Celina (org.). (1999): As Instituições brasileiras da Era Vargas. Rio de Janeiro: Fundação Getúlio Vargas. p.35-54.

LOBO, Francisco Bruno (1980): UFRJ: Subsídios à sua história. Rio de Janeiro: UFRJ.

MACHADO, Lia Osório (1995): Origens do pensamento geográfico no Brasil: meio tropical, espaços vazios e a idéia de ordem (1870-1930). In: Castro et.al (orgs.) Geografia Conceitos e Temas. Rio de Janeiro: Bertrand Brasil. p. 309-351.

MACHADO, Mônica Sampaio (1999a): A contribuição de Delgado de Carvalho aso estudos geográficos brasileiros a partir da obra Le Brésil Méridional. In: Revista do Departamento de Geografia da Universidade do Estado do Rio de Janeiro. 
Rio de Janeiro. In: Primeiro Simpósio de História do Pensamento Geográfico. UNESP/Rio Claro. p147-151.

(1999b): Uma contribuição à história institucional da geografia carioca In: Primeiro Simpósio de História do Pensamento Geográfico. UNESP/Rio Claro. p.147-151.

MONTEIRO, Carlos Augusto de Figueiredo (1980): A Geografia no Brasil (19341977): avaliação e tendências. São Paulo: Instituto de Geografia. FFLCH-USP.

MOVSCHOWITZ, Maria Raquel Vidigal (1980): O Ensino da Filosofia na Universidade Brasileira. Rio de Janeiro: dissertação apresentada no Departamento de Filosofia da UFRJ.

OLIVEIRA, Lúcia Lippi. Vargas (1999): Os intelectuais e as raízes da ordem. In: D'ARAUJO, Maria Celina (org.). As Instituições brasileiras da Era Vargas. Rio de Janeiro: Fundação Getúlio Vargas. p.83-96.

PENHA, Eli Alves (1993): A Criação do IBGE no contexto da centralização política do Estado Novo. Cadernos Memória Institucional. Rio de Janeiro: CDDI IBGE.

RAJA GABAGLIA, Fernando Antônio (1947): Geografia política e engenharia . Boletim Geográfico. Rio de Janeiro: IBGE. v. 55, 819-22.

RAMA, Angel (1985): A cidade das Letras. São Paulo: Brasiliense.

RIBEIRO, Darcy (1985): Aos Trancos e Barrancos: como o Brasil deu no que deu. Rio de Janeiro: Editora Guanabara.

SCHWARCZ, Lilia Moritz (1998): As Barbas do Imperador: D. Pedro II, um monarca nos trópicos. São Paulo: Companhia das Letras.

SCHWARTZMANN, Simon (1983): Estado novo: um auto-retrato, Brasília: UNB, Arquivo Gustavo Capanema.

VELLOSO, Mônica Pimenta (1996): Modernismo no Rio de Janeiro. Rio de Janeiro: Fundação Getúlio Vargas.

Anuário do Instituto de Geociências da UFRJ. Rio de Janeiro: UFRJ. volume 18 1995.

Cadastro Nacional de Arquivos Federais. Ministério da Justiça. Arquivo Nacional. Brasília: Presidência da República 1990. 